\title{
The Research on the Online Tutoring Based on the Teaching Team of Public English of the National Open University in China
}

\author{
Li Cao \\ Jilin Radio and TV University ,Changchun, 130022, China \\ Email:cljltv_7473@163.com
}

Key words: Online Tutoring; Teaching Team; Public English

\begin{abstract}
Online education, as a new form of educational innovation, is spreading rapidly around the world. Based on the research of Public English online tutoring design and practice by the teaching team, the paper discusses the implementation and evaluation of the online tutoring of Public English. It showed the building of the learning resources, interaction construction, and learning evaluation to explore a new "learner centered" learning support service mode for distance learning so as to stimulate students' interest in learning, reinforcement learning initiative of students, improve the self -learning ability. It hopes to give a contribution to the building of the lifelong education system in China.
\end{abstract}

\section{Introduction}

In July 31, 2012, the National Open University was officially inaugurated in the Great Hall of the People, is a new kind of university in distance education. At present, there are 68 colleges and universities, including the National Open University, to carry out the modern distance education project. The National Open University was founded on the basis of the Central Radio and Television University, and has begun to carry out the Open Education (Modern Distance Education) since 1999. The open education, in which the tutors and the students are in quasi permanent separation, focuses on the students' self-learning supplemented by face-to-face lecture. With the development of the modern distance education, online learning has become an important way for adult students to study independently. The exploration, design and integration of the distance education online learning resources, and the construction of the distance learning platform for learners provide a broad space for learning. In English teaching, people pay more attention to the comprehensive application of various media text, audio, video and animation, continuously explore and introduce new kinds of network teaching mode, to provide a variety of learning support services for students. But the current problem is that there is a variety of online learning resources with lack of pertinence and interest. The students facing the mass information, would be at a loss what to do. The online tutoring lacks interaction and interest, and the teaching activities are not organized well, being lack of the teaching strategies, which can't effectively stimulate the students' learning enthusiasm, is not favorable for the students' learning initiative to play.

Our school as a branch of the National Open University, according to the building spirit of the National Open University, actively makes the reformation of the intellectuals training model and evaluation model. In the reformation of the intellectuals training mode, we try to make the course innovation, and carry out the online tutoring to provide the students with a set of learning resources, learning activities, learning evaluation and learning support services, so as to promote the students' self-learning ability.

In order to improve the teaching quality of the Public English course, we have been strengthening the construction of the dynamic teaching information and resources on the Internet. As of 2012, for Public English class, we recorded a 40 video resources, provided 200 tutorial articles, and built 5 CAI courseware. With the reformation of the teaching mode, how to explore an online teaching mode with a certain significance in accordance with the characteristics of the English course, for the majority of teachers, is a very urgent problem. In this context, we carry out the study of the online tutoring of Public English. 


\section{Research objective}

Most of the subjects of this course are the adults who are poor in English, and less in practice. Through this research, we try to make full use of the power of TVU system and the advantages of the team teaching, explore the effective online tutoring to enrich the online learning resources, improve the learning support service level, stimulate students' interest in learning and improve the students' learning effect.

\section{Research hypothesis}

We take the Jilin Branch of the National Open University as the practice base guided by the theory of distance education , construct the online tutoring mode based on the teaching team of the system, design the diverse learning support services, to solve the problems of the monotonous tutoring activities and the lack of pertinence, interaction , interest and self- learning ability.

\section{Research theory}

The teaching design of Public English is based on the theory of constructivism learning (constructivism), which was started in 90s. The theory holds that knowledge is not taught by teachers, but obtained by the learner in a certain social and cultural background (the situation), with the help of other people (teachers and learning partners) , using the necessary learning resources, by way of meaning constructing.

The theory of constructivism is a hot research at home and abroad. On the one hand, the theory of Constructivism emphasizes student-centered, makes the students change from the passive recipients of external stimuli and knowledge to the learners with the self-learning ability. On the other hand, the theory of Constructivism also requires teachers to change from the people who teach knowledge to the guiders, supporters and facilitators.

The Public English online tutoring design in Open University is guided by the theory, focuses on how to embody the learner-centered ideology. The course content, the role of teachers and students, the online tutoring interaction and the learning evaluation should be discussed.

\section{Research process}

\section{Formation of the course teaching team}

Our school has many branches in Jilin province, Governed by the school head quarter, each of the branches is in charge of its own teaching for its own students. In recent years, the whole school system has employed many English teachers, The teaching team is strong. In order to make full use of the advantages of the teaching team, we set up English teaching team. The teaching team members consist of 11 people, of which 7 people from the headquarter, 4 people from Tonghua branch, Jilin city branch, Huadian branch and Yanbian branch respectively .In which, there is 1 professor, 2 associate professors, 7 lecturers and 1 assistant. The team leader is responsible for the overall planning, teaching design, evaluation design, online instructional design and the production of some resources. Team teachers are responsible for the production of resources and online tutoring activities..

\section{Online tutoring design of Public English Course}

\section{Create lively and interesting video resource}

In order to provide more lively and interesting learning resources for students, we produced high-quality video resource. The instruction is provided with the corresponding animation, to help students better understand the language knowledge. In addition, in order to expand the students' knowledge of English, to stimulate students' interest, we also recorded the simulated verbal communication resources and the cultural salon resources for learners. 


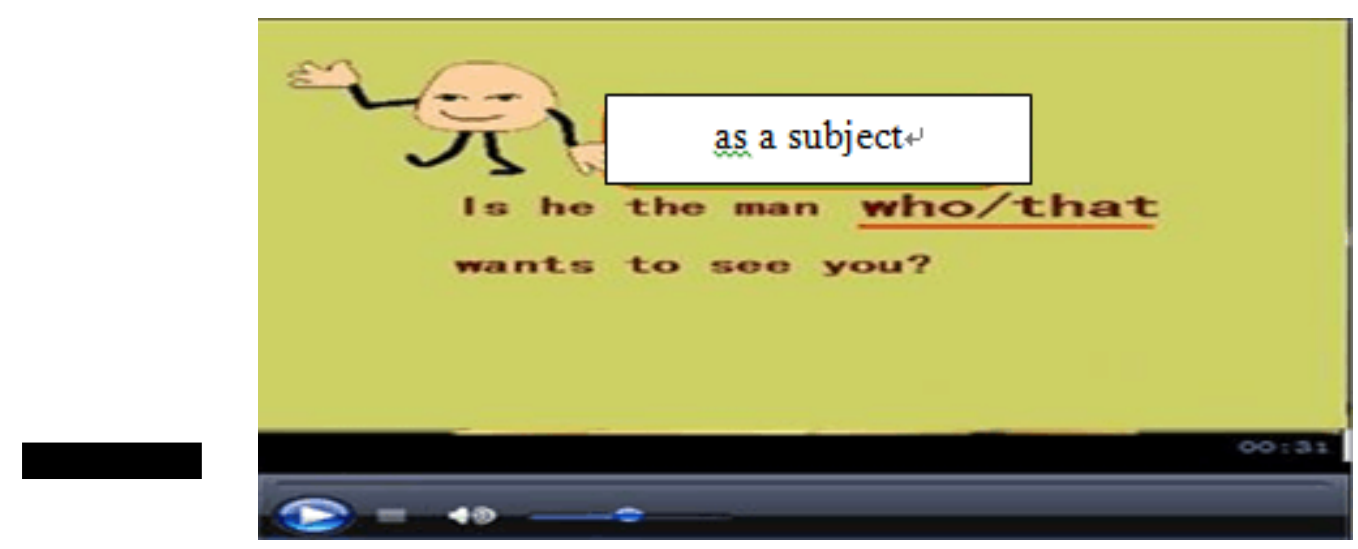

\section{Create online practical resources with human -computer interaction}

According to the students' lack of the practice opportunities ,we also made oral imitation resources, which provides the virtual verbal communication environment for the students, students can participate in the virtual activities and make the voice recording as well as make the comparison with the original.

Hr. Smith tour group goes through inmigration procedures as a group.

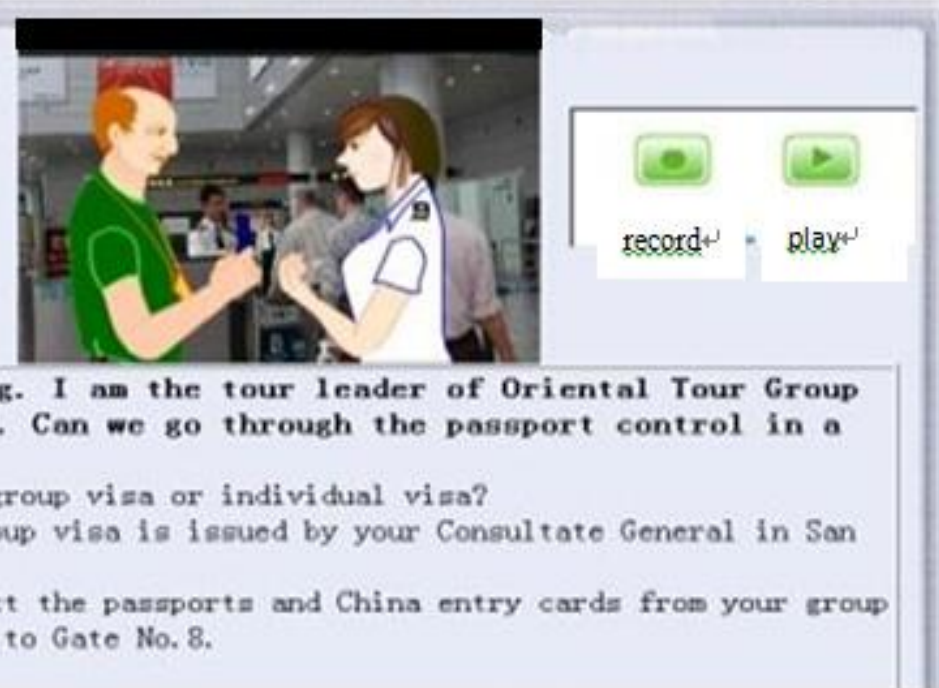

In the Public English teaching ,the most difficult thing for the students is the writing section. We provide a set of simulation writing resources for students, who can make the practical writing, which can be corrected autonomously when wrong and voice instruction is offered.

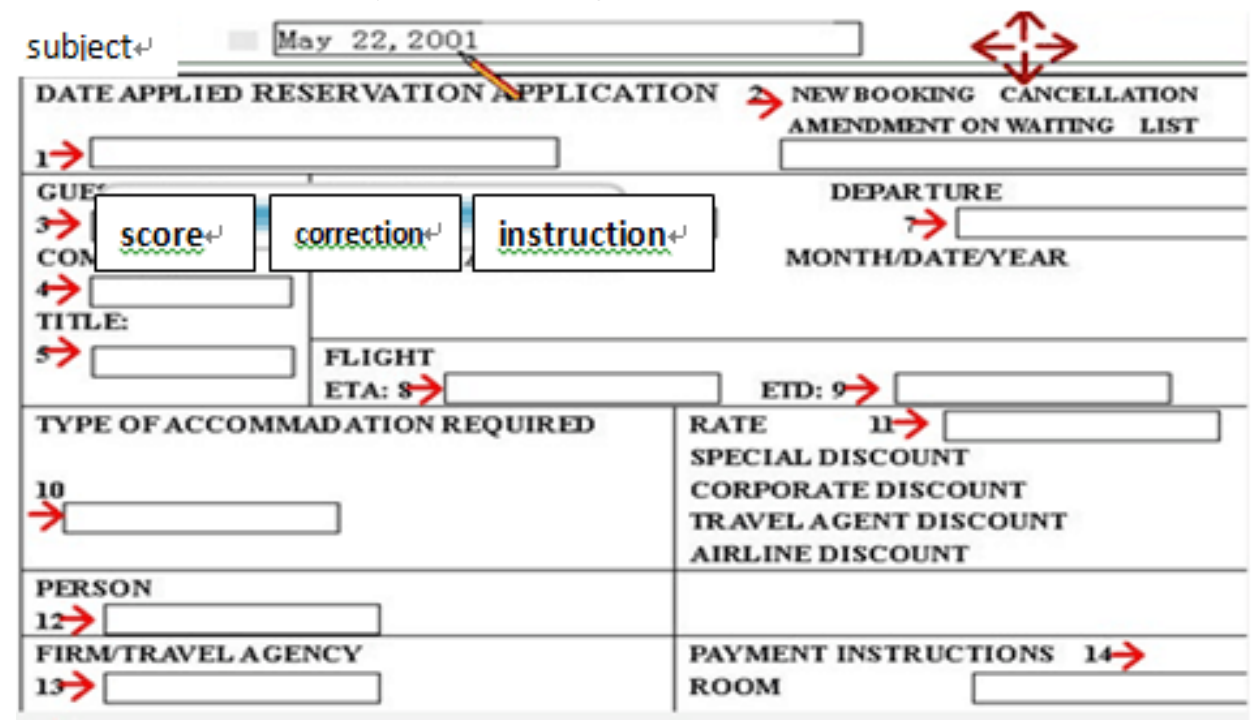




\section{Carry out the online flipped class}

In the online flipped class, the students, rather than the teachers, present the knowledge which they have got through the learning resource, The teacher gives the students the presentation tasks in advance. The students are divided into several groups. Each of groups makes the presentation. Then the teachers give the feedback and the guidance.

In the teaching of Pubic English, we make a preliminary application of the online flipped class model. Before the start of the flipping class, the leader of the teaching team issues the topics in the discussion platform in the pinned way, and give the students 2 weeks to prepare. We focus on the English examination to give the tutorial, design targeted learning theme, and the same theme is divided into different modules, and then to guide the students on different subjects, to make use of the resources to learn by themselves. Then the learning groups make the presentation respectively. The group leader is responsible for the instruction, and other students give supplement and comment. The tutor tests students' mastering of knowledge through continuous questions, and the completion of each task of students were evaluated. Finally, the tutor gives the summary. The following figure is the model of the online flipping class.

Facing the students of Public English in the whole province, the members of the teaching team are responsible for the tutoring of the different districts respectively. The leader is responsible for the discussion topics, and the other team members are responsible for the questions answering to provide students with a full range of learning support services. And through telephone, e-mail, QQ, the teaching team timely answers the questions for students.

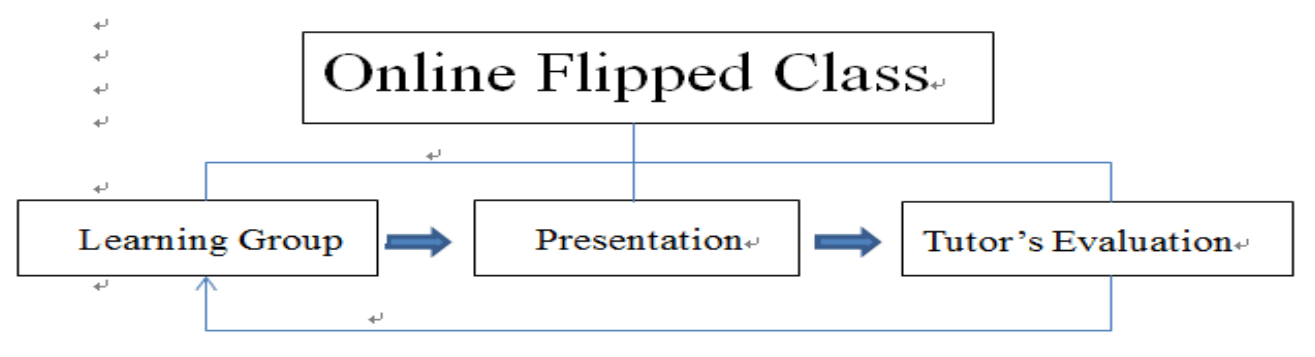

\section{Focus on the evaluation of learning process}

In English teaching, we focus on the supervision of the learning process of students taking the learning process evaluation instead of the final examination. As long as the students learn the relevant learning materials, to achieve the required learning time and download the material for a certain times ,the learning evaluation system will automatically open for students.

\section{Result}

\section{An effective interactive platform for teachers and students}

The teaching team provides multiple learning services for students. Considering the learning needs of students, we have built a variety of digital learning resources, set up the online learning platform and practical teaching platform on which a set of learning resources, learning activities, and evaluation are provided. It effectively promote the interaction between teachers and students, and provide the chances for the students to communicate in English, express their views or seek guidance and overcome the lack of the favorable factors in language environment for the distant learners. It helps the students to solve the problems in self-study and strengthen individual counseling, eliminate the strangeness and loneliness, effectively narrowing the distance between teachers and students. It also cultivates the students' mutual communication skills and ability, improve their self- learning ability.

\section{The improvement of the learning effects}

We conducted a questionnaire for the students. The results of the questionnaire show that the students are satisfied with in the multimedia courseware, the practice teaching mode, online tutoring 
activities and the teachers' support services. The majority of students think that the video resources give the detail instruction, with the characteristics of being vivid, interesting and interactive, favorable for the self -learning. The practice teaching has strong pertinence with simple and flexible operation, and the tasks are easy to be completed. The tutoring class is rich in content, not only helps to grasp and understand the curriculum knowledge, but also helps to have the knowledge expansion. The students have higher learning enthusiasm.

The students' participation in online learning is getting better and learning initiative is getting stronger. The majority of students have achieved good results, the passing rate of the course has come to $97 \%$.

\section{Conclusion}

The results show the online tutoring model of Public English is effective, while some problems such as individual counseling would be explored better. We will continue to make a study in the future.

\section{Acknowledgement}

In this paper, the research was sponsored by Jilin Provincial Educational Department (Project No.[2013]621) and Jilin Radio and TV University.

\section{References}

[1] Samuda, V. \&C. Madden. 1984. Task-based test: Testing as a reflection of classroom methodology [J]. Papers in Applied Linguistics , Michigan, (1): 84-94

[2] Tan S, Hung D. Beyond Information Pumping: Creating a Constructivist E-Learning Environment [J].Educational Technology, 2002, 42(9/10):50-51.

[3] Johnston Chris. E-learning to get own quality initiative [J].Times Higher Education Supplement, 2004(12):8-8.

[5]Young Carol Bormann Johnson Nancy HessKen I'm Considering Teaching Online

What Questions Should I Ask? Online classroom Feb.2006.

[6]George Siemens Connectivism: A Learning Theory for the Digital Age Instructional Technology \&Distance Learning 2(1) 2005 3-10. 